\title{
Understanding Gender-based Violence: Evidence from Kilimanjaro Assessment of Rombo and Moshi Rural
}

\author{
Jane Saffitz \\ School of Social Work, \\ Columbia University, \\ Nerw York \\ E-mail address:jls2240@columbia.edu.
}

\begin{abstract}
This paper presents findings from an empirical study on the prevalence and beliefs surrounding gender-based violence $(G B V)$ in the Kilimanjaro region. The analysis and ensuing discussion is the result of a representative sample of adults $(n=384)$ surveyed in two districts, Rombo and Moshi Rural, in Kilimanjaro, Tanzania. In contrast to previous research of a similar nature, which has focused primarily on the frequency of violence, this study devotes significant attention discerning the level of social acceptability among its victims and perpetrators situated in a legal and cultural framework. I find that alcohol consumption and the number of deceased children within a household have a direct correlation to incidences of $G B V$ while an individual's level of education and degree of financial independence are inversely related to rates of violence. The influence of bride price and polygamy is inconclusive. Finally, Ifind that although a portion of the population believes women should have decision-making capabilities, patriarchal institutions and a culture that relegates women as inferior have a significant impact on individual attitudes among men and women to preserve the status quo. These results suggest a greater need to promote a culture of egalitarianism in a sensitive and relevant manner.
\end{abstract}




\section{Introduction}

Gender-based violence (GBV) is culturally patterned. Previous research shows that GBV is most prevalent in societies with rigid gender roles or in patriarchal communities in which male dominance is engrained in a masculine identity (Heise 1998). This paper reports results from a study conducted in the Kilimanjaro region of northern Tanzania. Its purpose is two-fold as the author seeks to identify the factors associated with high incidences of GBV and to understanding prevailing attitudes among adults. This report focuses primarily on violence against women by intimate male partners, as results overwhelmingly show this to be the most prevalent (though not the only) form of GBV.

Like much of sub-Saharan Africa, the Kilimanjaro region is host to a patrilineal society in which inheritance is traced through fathers. Men benefit from the preservation of the status quo and typically hold more decision-making capabilities than their female counterparts. Evidence of strong patriarchal institutions can be found in the use of a bride price, the practice of polygamous marriages, emphasis on fertility, significant expectations to marry, and paternal control in choosing suitable partners for marriage (McCloskey, Williams, and Larson N.d.). Additionally, a highly stratified sexual division of labor and an inherently unequal distribution of resources contribute to a society in which women are disadvantaged. Because women are reared to work inside the home and are seen as economically less valuable than men, they often have less access to education which perpetuates their seemingly inferior status. Their plight is further compromised by the frequent denial of property ownership, which, in conjunction with a lack of education, makes acquiring assets and increasing human capital exceedingly difficult.

\section{Ecological Framework and Social Learning Theory}

An 'ecological framework' is helpful in understanding the complex interactions of gender and power. This model emphasizes certain variables within an individual's social environment and seeks to understand GBV through the interplay of these variables. Heise (1998) best explains this framework as four concentric circles, the first of which corresponds to an individual's personal and biological history. The second circle represents one's immediate context, which most frequently is the family. The third circle accounts for institutions and social structures that affect the individual. Lastly, the fourth circle is representative of one's economic and cultural environment.

This model provides insight into the factors at play in the Kilimanjaro region. On the more micro level are factors such as alcohol consumption and marital conflict, both of which are usually correlated with GBV. In the outermost circles are factors such as the degree to which a woman is considered property and the acceptance of violence as an appropriate expression of disapproval. This study seeks to account for the variables 
at play in all levels of one's social environment by discerning which factors put women most at risk and by assessing the degree to which GBV is socially acceptable.

Also useful in understanding high frequencies of GBV is the social learning theory, which posits that behavior is learned by observing and re-enacting the behavior of others, especially role models. Just as gender roles and social norms are learned within a larger cultural context and passed from one generation to the next, so too is behavior (Uthman, Lawoko, and Moradi 2009). Young boys are socialized according to established norms and are expected to adopt and operate within these beliefs. This pressure, while subtle, infiltrates every aspect of the social environment as boys are taught at home, in school, and in the community that their primary responsibility will be to marry and support a family. An inability to provide financially likely causes feelings of inferiority and consequently threatens one's masculine identity. One compensatory response is to assert power in other ways, often through physical and sexual aggression (Mzinga 2002).

\section{Statutory, Customary, and Religious Law}

Tanzanian laws regarding GBV are quite progressive compared to other sub-Saharan nations. However, there is a wide discrepancy between legislation and existing behavior in local communities, as law enforcement and a woman's tendency to remain silent have hindered national efforts to reduce GBV. The Constitution of the United Republic of Tanzania specifically prohibits discrimination and references gender as an unlawful basis for discriminatory acts (Article 13[5]). The Law of Marriage Act of 1978 states that the government of Tanzania recognizes monogamous and polygamous marriages and grants each party the right to property. The government also banned corporal punishment and cited brutality as an acceptable reason for divorce. The Sexual Offences Special Provisions Act of 1998 sought to safeguard a woman and children by expanding the capacity for punishment. SOSPA additionally criminalizes female genital cutting for individuals under eighteen and specifies a woman's right to compensation by the perpetrator if any aforementioned stipulation is violated (Kijo-Bisimba N.d.).

Despite ratification of the United Nations' Convention on the Elimination of all Forms of Discrimination against Women (CEDAW), both international and statutory laws have been insufficient in protecting vulnerable women against the still powerful religious and customary laws that dictate the course of action in many villages throughout the region. Specifically, Chagga law states that female children are prohibited from inheriting property from a land-owning father if he has a son. Like the Chagga, Pare traditions surrounding marriage often include a bride price, which perhaps reflects the belief that a bride is a transferable commodity from her father to her husband (Rutazaa 2005). Women are frequently disadvantaged by religious law as well because both Islam and Christianity - each roughly 40 percent of the population - find divorce morally questionable (Bastien 2005). As a result, women face pressure from religious leaders and 
respected community members to remain in marriages that may be detrimental. Thus, the legislation passed at the federal level does not necessarily reflect the beliefs of those who feel more allegiance towards either religious or customary law.

While acts such as Tanzanian President Jakaya Kikwete's UN-sponsored 'Say No to Violence against Women' suggest movement toward a more egalitarian society (Citizen 2008), they are discordant with the patriarchal nature of customary and religious practices that promote female submission (Rutazaa 2005). This discrepancy is supported by data from the 2004 Tanzania Demographic Health Survey (TDHS) in which 42 percent of men and 60 percent of women validated wife beating as an appropriate and typical aspect of society. In a 2005 study by the World Health Organization in Dar es Salaam and Mbeya, 41 percent of 'ever-partnered' women reported experiencing physical or sexual abuse by a partner at some point in their lifetime (Ministry of Planning, Economy, and Empowerment 2006). These alarmingly high numbers necessitate further investigation into the precise nature of GBV so that government leaders and members of the NGO community can more effectively promote the espousal of egalitarian beliefs among women and men and children.

\section{Empirical Context}

The Kilimanjaro Region is located in northeastern Tanzania and borders Kenya to the north, Tanga region to the southeast and Arusha region to the southwest. Kilimanjaro is comprised of six administrative districts (see Figure 1), five of which are rural (Moshi Urban being the exception). Within the six districts there are 121 wards and 449 villages (National Bureau of Statistics \& Kilimanjaro Regional Commissioner's Office [KSEP], 2002). This study contains data from Rombo and Moshi Rural and analyzes the experiences and beliefs of individuals residing in fourteen villages in five wards.

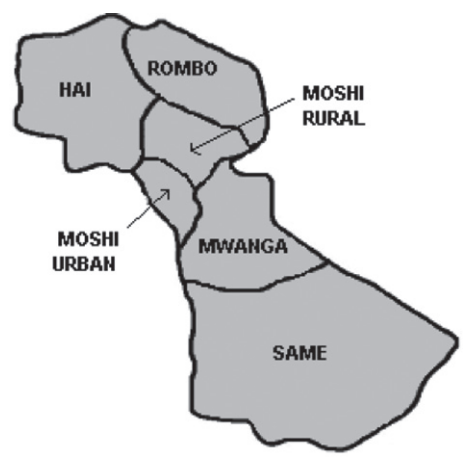

Figure 1. District Map of the Kilimanjaro region 
Rombo has a population of 245,716 individuals. The three wards represented are Tarakea Motamburu, Mamsera, and Mrao Keryo. Mamsera and Mrao Keryo are categorized as rural wards while Tarakea Motamburu is classified as a mix of both rural and urban areas. Tarakea Motamburu has a population of 17,573 individuals in two villages, Kikelewa and Mbomai. Mamsera has a population of 9,620 and is comprised of three villages, Mamsera Kati, Mamsera Juu, and Mamsera Chini. Mrao Keryo has a population of 8,107 and also contains three villages, Mrao, Keryo, and Mmomwe (Population and Housing Census 2002).

Moshi Rural is more densely populated with 401,369 individuals. The two wards surveyed are Uru Shimbwe and Mabogini, both of which are rural. Uru Shimbwe has a population of 5,574 and has two villages, Shimbwe Chini and Shimbwe Juu. Mabogini has a population of 20,544 in four villages, the largest of which is Mabogini. The others include Chekerini, Mtakuja, and Mvuleni (Population and Housing Census 2002). All villages were surveyed although the majority of respondents were from Mvuleni.

According to KSEP (2002), approximately 75 percent of the population in Kilimanjaro live in rural areas where agriculture is the dominant line of work, accounting for 69 percent of gross domestic product earnings. Because the vast majority work as farmers, accessing and owning land is crucial. Often women are expected to cultivate their husband's land, which does not necessarily result in reaping any output (Gonzalez-Brenes 2004). KSEP estimates that women, who account for 51.7 percent of the population, work an average of 16 hours a day and are the foremost contributors to production.

\section{Characteristics of Gender-Based Violence}

Previous research suggests that household violence is more likely when men have multiple sexual partners, consume alcohol in excess, or do not contribute financially to the wellbeing of their children. (Heise 2002, Hinden 2003) GBV is also more likely to be present in households in which women have low levels of education, have trouble conceiving, or do not contribute to household income (Gonzalez-Brenes 2004). Scholars have also identified a link between GBV and HIV/AIDS, which could be attributed to violence as the result of disclosing a positive HIV status or to a woman's inability to negotiate safe sex with her partner (Kimuna and Djamba 2008). The use of a bride price is also considered to increase a woman's chance of experiencing GBV as the practice may be interpreted by a man to imply unrestricted sexual access to his wife (Uthman, Olalekan, Lawoko, and Moradi 2009).

In assessing the effects of household composition on GBV, scholars have found a negative correlation between the number of male children and the prevalence of violence and a positive correlation between the death of a male child and the likelihood of violence (Heise 2002, Hinden 2003). This is perhaps due to a man's increased satisfaction 
with his wife for bearing male children, to male children having more opportunities to contribute to the family income, or to a male child's ability to protect his mother. GBV is positively correlated with the number of children in a family, although, interestingly, there is no relationship between the presence female children and incidences of GBV (Gonzalez-Brenes 2004).

While there is a growing body of research investigating gender-based violence in the developing world, the majority of studies have focused on prevalence and its determinants without adequate attention to the underlying beliefs that propagate violence (Hinden 2003). Nonetheless, a general trend in data suggests that both women and men agree that violence is acceptable under certain circumstances. Data on intimate partner violence in Zimbabwe suggests that refusing sex, neglecting children, and arguing are commonly thought of as inexcusable offenses that justify violence (Hinden 2003). Additionally, Hinden found that partners who share decision-making are less likely to resort to violence. The present study aims to gain further clarity regarding both female and male attitudes towards GBV in addition to testing the relationship between attitudes and frequency. Socio-demographic variables, in conjunction with data regarding household composition and support from peers, add further depth to the study by situating beliefs in a larger context of relevant variables.

\section{Conceptual Model and Hypotheses}

The questions in this study are based on factors that have commonly been associated with GBV. These factors can be divided into the following categories: household sharedexperience characteristics, including socioeconomic status, type of union (monogamous or polygamous), religious affiliation, alcohol consumption, number of children alive and number of children deceased (Kimuna and Djamba 2008). The second and third categories include data regarding the respondent's socio-demographic characteristics and the socio-demographic characteristics of the respondent's partner. The fourth category considers the relative importance of decision-making authority and the degree to which a union is egalitarian. The fifth category explores circumstances in which violence is acceptable, and the sixth category is comprised of a list of statements designed to test prevailing attitudes to which the respondent must agree or disagree.

Based on the aforementioned literature review, it is hypothesized that a high percentage of women will find gender-based violence socially and morally acceptable. The author anticipates that both a woman's degree of economic independence and her level of education will be key factors in decreasing the likelihood of abuse as both lead to female empowerment. It is also probable that polygamous couples will have higher incidences of GBV, but do not necessarily find it more socially acceptable than those in monogamous relationships. This is based on the assumption that there is more likely to be a power differential among polygamous couples. Accordingly, violence is predicted 
to be more common among non-egalitarian couples where decision-making is not a joint process (Bastien 2005, McCloskley, Williams \& Larsen, N.d.). In terms of positive correlates of GBV, the author hypothesizes that men's alcohol consumption and the presence of a bride-price will increase rates of violence against women.

\section{Methodology}

For the purposes of this study, gender-based violence was defined by physical and sexual violence, and thus did not inquire into the nature of emotional or psychological abuse. The dominant beliefs among the populations surveyed are based on patrilineal foundations, which elevate men to a superior status compared to females and bestow greater decision-making capabilities. While this does not imply that gender-based violence is comprised solely of male perpetrators and female victims, it is evident from the data that men experience significantly less violence than women in Kilimanjaro.

Data collection occurred in the form of a survey which included socio-demographic variables, measures of household decision-making, circumstances that warrant violence, and attitudes regarding GBV. Surveys were conducted in either English or Kiswahili. Surveys were thought to be a more effective way of measuring the relationship between socio-demographic variables and rates of GBV than focus groups or interviews. Key variables included one's number of sexual partners and one's HIV status - both of which individuals were more likely to report on paper. It is generally known that women in Kilimanjaro do not often admit to violence committed against them and so it was assumed that focus groups or interviews would not be as conducive to speaking openly about GBV. Furthermore, a survey would be better able to detect under-reporting (providing overtly false or less than entirely truthful responses), which was identified early as a potential concern.

\section{Sampling}

Date collection spanned from the 15 June to 20 July 2010 . The three-part survey was first tested on a representative sample $(n=48)$ of adults 15 years and older in three villages in Tarakea Motamburu. Afterward, it was decided that training and compensating a trusted local government authority to administer the surveys would reduce error, as individuals had difficulty understanding, seeing, and reading the questions. Participants were selected at random from a list of individuals who expressed interest in a two day seminar about human rights. They were compensated for transport and provided with an afternoon meal. In all wards in Rombo, surveys were administered by the Ward Executive Officer who was compensated 500 Tanzanian Shillings (Tshs) for each survey administered (roughly $0.35 \mathrm{USD}$ ). In each instance, this individual was trained to explain 
anonymity and confidentiality to each participant, to administer the survey in a private setting, and to administer the survey at random to all adults above the age of 14 . The author was present for all meetings with Ward Executive Officers and arranged to collect the surveys the following week. In Mabogini, however, the Ward Executive Officer was unable to administer surveys. In her absence, it was decided that the surveys would be administered during a weekly gathering of village women by their group facilitator, a revered woman who also worked as a translator. Consent was gained a week prior to data collection and confidentiality was already engrained in the collective conscience of the group as women were fined for discussing the details of their meetings with any outsider. In total, the data in this study $(n=384)$ represents a random sample of adults from seventy-one sub-villages, fourteen villages, five wards, and two districts in the Kilimanjaro region.

\section{Socio-demographic Variables}

Socio-economic status was tested in two questions, the first of which asked about monthly income. To avoid a large proportion of non-responders and to gauge socio-economic status accurately, there was a follow up question asking individuals to select from a list of possessions present in their household. Possessions included land, bicycle, television, refrigerator, stove or heating device, radio, cattle, and bedding. Respondents were then categorized as having a low socio-economic status (three or fewer assets circled), a moderate socio-economic status (four to six assets circled) or a high socio-economic status (seven to nine assets circled).

Prevalence of GBV was tested in three questions, the first of which asked participants to identify the acts that had been committed against them by their partner at some point in their lives. The second question listed the same variables but limited the time frame to the past twelve months. Acts of violence included being slapped, kicked or dragged, pushed or shaken, punched, having one's arm twisted, having an object thrown at the participant, being forced to have sex, and being forced to engage in a sexual act. A third question asked participants whether their partner had ever caused them to fear for their lives. Violence was measured as non-existent, prevalent but not severe, or severe. Participants were classified as experiencing severe violence if they checked three or more variables and confirmed that they had feared for their lives. It was not necessary for violence to have occurred in the past twelve months for an individual to have experienced severe violence, as those who were widowed, divorced, or separated may have recently experienced a safer living environment. 


\section{Measures of Decision Making and Circumstances that Warrant Violence}

One set of questions asked participants to identify which household member had the decision-making power in different circumstances. Four questions asked respondents to identify the degree to which they agreed with statements beginning, "It is acceptable for a person to beat his or her partner if..." Each circumstance was analyzed separately to determine the relationship between selected demographic variables (e.g. married vs. single) and prevailing beliefs regarding the circumstance. These questions were loosely based on previous research regarding intimate partner violence in Zimbabwe (Hinden 2003).

\section{Results and Discussion}

Of the 384 participants surveyed, females comprised 52.6 percent of the population, while males accounted for 47.4 percent with everyone reporting. There was a fairly even distribution of participants among the wards, ranging from 17.7 percent in Mabogini to 23.4 percent in Mrao Keryo. The ethnic composition was overwhelmingly Chagga (70.8 percent) followed by Pare (11.5 percent). 77.3 percent were Christian. With the exception of gender, the variables listed above had no significant relationship with the occurrence or absence of GBV.

Roughly half (50.2 percent) of the population was between the ages of thirty-five and fifty-four, expectedly higher than any regional average because participants under fifteen were unable to participate. Only 10.2 percent entered secondary school while 77.0 percent completed Standard 7 or below with two participants not responding. In terms of the participants' relationship status, 71.1 percent were married and only 3.1 percent - two participants - were divorced. The high marriage rate speaks to the cultural expectation to marry and the acceptability of remarriage after a partner dies or moves elsewhere. A bride price was involved in 39.8 percent of marriages, although ninetyseven participants did not report. Data support previous research suggesting that the dominant area of work is in agriculture as 55.7 percent of participants were farmers. For the total population, 56.1 percent earned less than 20,000 Tshs. This is roughly equivalent to forty-four cents per day in US dollars.

\section{Socio-demographic Variables Correlated with Gender-based Violence}

The author hypothesized that a woman's level of education would be inversely related to her chances of becoming a victim of GBV as education leads to female empowerment and independence. Data yielded interesting observations for women reporting GBV in their lifetime and women reporting in the past twelve months. Of the 202 females 
experiencing GBV in their lifetime, there was not a single case of severe GBV reported among women who finished Form 4 or higher and for women who completed vocational training. Moreover, only two women who completed at least some secondary two women reported severe GBV over the course of their lifetime. While this statistic speaks to the low educational attainment of women in general - a problem entirely its own - the data also suggest that prevalence of GBV among women decreases as years of schooling increase. For data specific to women experiencing GBV in the prior year, see Table 1.0.

Table 1.0 Prevalence of Gender-based Violence Against Women in the Last 12 Months versus Level of Education Completed

\begin{tabular}{lcccc}
\hline & No GBV & Yes (not severe) & Yes (severe) & Total \\
\hline No education & 3 & 7 & 1 & 11 \\
Some Primary & $(27.3 \%)$ & $(63.6 \%)$ & $(9.1 \%)$ & $(100.0 \%)$ \\
& 2 & 18 & 10 & 40 \\
Standard Seven & $(30.0 \%)$ & $(45.0 \%)$ & $(25.0 \%)$ & $(100.0 \%)$ \\
& 66 & 26 & 15 & 107 \\
Some Secondary & $(61.7 \%)$ & $(24.3 \%)$ & $(14.0 \%)$ & $(100.0 \%)$ \\
& 7 & 7 & 0 & 14 \\
Form Four and & $(50.0 \%)$ & $(50.0 \%)$ & $(0.0 \%)$ & $(100.0 \%)$ \\
beyond & 8 & 1 & 0 & 9 \\
Vocational & $(88.9 \%)$ & $(10.1 \%)$ & $(0.0 \%)$ & $(100.0 \%)$ \\
Training & 5 & 3 & 0 & 8 \\
Total & $(62.5 \%)$ & $(37.5 \%)$ & $(0.0 \%)$ & $(100.0 \%)$ \\
& 101 & 62 & 26 & 189 \\
& $(53.4 \%)$ & $(32.8 \%)$ & $(13.8 \%)$ & $(100.0 \%)$ \\
\hline
\end{tabular}

It was also predicted that a woman's degree of economic independence or her ability to contribute to the household income would reduce her chances of experiencing GBV. Data confirm this hypothesis and support a growing a body of research which found similar results. Not only does prevalence decline as income rises, but no woman who reported an income of 101,000 Tshs or higher also reported ever fearing for her life. An income of 101,000 Tshs is roughly equivalent to earning sixty-seven USD per month. Among the 106 women who earn 50,000 Tshs, 65.1 percent had at some point feared for their lives.

The author predicted that the presence of a bride-price and a man having multiple partners would both increase a woman's chances of becoming a victim of GBV. However, these results were less clear. In comparing the presence of a bride-price to the number of women who have experienced GBV at some point in her lifetime, we found that 
bride-price had a negligible impact. In looking at women who experienced non-severe GBV, 33.3 percent had marriages that did not include a bride-price while 32.9 percent answered the question of bride price in the affirmative. For women who experienced severe GBV during their life-course, 38.1 percent reported no bride-price while 37.8 reported in the affirmative. There is also little discrepancy when looking at the number of women who have ever feared their lives according to whether they had a brideprice. Although the survey did not specifically inquire as to whether the bride-price was consensual, cultural norms suggest that women had little to no agency in negotiating the presence or the terms of the bride-price. It is important to note that a significant number did not respond to the question of bride-price (44.4 percent for non-severe and 22.2 percent for severe GBV). Thus, we can identify no statistically significant relationship between bride-price and GBV.

Data showed no statistically significant relationship between men with multiple partners and female rates of GBV, which differs from previous research. Interestingly, the rate of non-severe abuse remained constant as a man's partners increased when measured against both women experiencing GBV at some point in their lifetime and women reporting for the last year. However, the prevalence of severe abuse increased for women reporting violence during their life span and decreased among women reporting GBV during the prior year. Here, the relationship between having multiple partners and rates of GBV is inconclusive.

The prevalence of GBV among women with husbands who consumed alcohol suggests that alcohol consumption and violence are positively correlated. When looking at nonsevere and severe violence over a woman's lifetime, there was a clear and consistent increase in the percentage of women who experienced violence as a function of the number of days a week her partner drank. The same was true for non-severe and severe violence among women in the last twelve months. In looking at the prevalence of violence over one's lifetime, there was essentially no difference between rates of GBV for women whose partners did not drink and women whose partners drank once or twice a week. Here the prevalence was 65.7 percent and 68.8 percent, respectively. When drinking increased to three or four times a week, the rate of violence increased to 62.9 percent. Alarmingly, when drinking exceeded four days a week, 85.7 percent of women experienced GBV during the life course.

Further proof lies in comparing 'no violence' to 'severe violence' when a partner consumed alcohol at least five times per week. The percentage of women who did not experience violence and whose partners drank alcohol no less than five days a week was 14.3 percent as opposed to 60.0 percent of women who experienced severe violence and whose partners also consumed alcohol at least five days a week. However, the same results did not hold true for women reporting only the previous twelve months, as evidenced in Table 2. It is important to keep in mind that, along with a small sample size in some instances, which the number of days per week a person drank is unrelated to the amount consumed each day. 
Table 2.0 Prevalence of gender-based violence against women (in the last 12 months) according to partner's alcohol consumption (in days per week)

\begin{tabular}{ccccc}
\hline None & $\begin{array}{c}\text { Yes } \\
\text { (not severe) }\end{array}$ & Yes (severe) & Total \\
\hline 0 & 46 & 19 & 11 & 76 \\
& $(60.5 \%)$ & $(25.0 \%)$ & $(14.5 \%)$ & $(100.0 \%)$ \\
$1-2$ & 11 & 6 & 2 & 19 \\
& $(57.9 \%)$ & $(31.6 \%)$ & $(10.5 \%)$ & $(100.0 \%)$ \\
$3-4$ & 19 & 11 & 7 & 37 \\
& $(51.4 \%)$ & $(29.7 \%)$ & $(18.9 \%)$ & $(100.0 \%)$ \\
5 or more & 14 & 21 & 6 & 41 \\
& $(34.1 \%)$ & $(51.2 \%)$ & $(14.6 \%)$ & $(100.0 \%)$ \\
Total & 98 & 62 & 26 & 186 \\
& $(52.7 \%)$ & $(33.3 \%)$ & $(14.0 \%)$ & $(100.0 \%)$ \\
\hline
\end{tabular}

It is also worth noting, however, that of 27.5 percent of the individuals who reported consuming alcohol at least five days a week were women. Question 6.5 asked respondents to determine how strongly they agree or disagree with the statement, "I wish my partner consumed less alcohol." In continuing with the population that consumes alcohol at least five days a week, 26.7 percent of men strongly agreed with this statement. Of the 27.5 percent of women who consume alcohol at least five times per week, 29.2 percent strongly agreed with this statement. Similarly, 76.2 percent of men who consume alcohol at least five days a week agreed with this statement, while for women this value was 23.8 percent. It is conceivable that men believe the social acceptability of consuming alcohol differs for men and women. Regardless, this data suggests that alcoholism is problematic in its entirety and should be sufficiently addressed because of the correlation between alcohol consumption and GBV.

Previous research has indicated a positive correlation between a woman's number of children and the likelihood of abuse. However, the author found no evidence to support this claim and, in some instances, saw rates of GBV decline as family size increased. A smaller body of literature has also investigated the impact of the number of deceased children, which, in this study, was particularly telling (Gonzales-Brenes 2004). Of the 113 females who had never experienced the death of a child, 63.7 percent had experienced GBV at some point in their lifetime. Of the forty-three females who had experienced the death of at least one child, 83.7 percent had experienced GBV at some time. This was hypothesized and was based on the notion that stressful life events such as the loss of a child increase a man's tendency to express himself violently. Along similar 
lines, previous research supports the notion that a friend of the same gender within close proximity (e.g., the same village) can mitigate stressful life events and thereby decrease the chances of GBV. However, the author found no relationship between rates of violence and the presence of a nearby friend of the same gender.

There was also not an apparent relationship between the number of deceased children in a family and rates of GBV. For women reporting non-severe incidents of GBV in their lifetime, rates of GBV actually decreased with the death of the first and second child and then increased when the number of deceased children increased to three or more. Nonsevere incidents for women reporting in the last twelve months yielded a slight increase as the number of deceased children increased, although again the small sample size makes this finding less significant. There was no clear relationship between the number of deceased children and the number of women reporting severe GBV either in their lifetime or in the span of one year. Nevertheless, 83.7 percent of women with at least one deceased child experienced GBV, while the overall percentage of women experiencing GBV was 69.7 percent. Participants were not asked to identify the sex of the deceased child, nor were they asked to confirm the year in which the child died. This means we can assume no causal relationship between the death of a child and rates of GBV, as it is conceivable that violent behavior existed prior to the death of the child. Future research is needed in this area to discern the precise impact of the child's death.

\section{Attitudes Regarding Gender-based Violence}

The author predicted a significant degree of social acceptability and tolerance for GBV among men and women. In some instances, women were more accepting of violence than their male counterparts. This was especially true among victims. For example, question 6.7 states, "Sometimes a man needs to beat his wife to teach her how to behave." 9.6 percent of women who were not victims of GBV in the past twelve months agreed with this statement while 29.3 percent of women who were victims in the past twelve months agreed. Here, the percentage of female victims who agreed was more than three times higher than the number of women not victimized by GBV. In this case, it is conceivable that recent victims of GBV had internalized the abuses committed against them and are now part of the status quo who, perhaps unknowingly, propagates such beliefs.

Moreover, women who had participated in patriarchal rituals or practices demonstrated less of a desire to change existing inequalities between men and women. Question 5.7 states, "Upon marriage, a woman becomes her husband's property." Interestingly, women whose relationships had never involved a bride-price were less accepting of this statement: only 48.6 percent of women who have did not have a bride-price either agreed or strongly agreed with this statement while 70.5 percent of women who had a bride-price either agreed or strongly agreed (eleven did not report). In contrast, 100.0 
percent of men who did not have a bride-price either agreed or strongly agreed with this statement while only 51.0 percent of men who benefited from a bride-price either agreed or strongly agreed. Thus, among participants with a bride-price, there was significantly more support from females for a cultural practice that was to their detriment.

This is not to say, however, that the data did not show a significant number of participants with largely egalitarian beliefs regarding gender-roles. Of the six questions that asked about decision-making power, four were answered with the highest percentage in the 'both' category, suggesting that some degree of joint-decision making occurred in Rombo and Moshi Rural. One exception had to do with decisions about food preparation, as 38.4 percent advocated for females to have sole decision-making powers. The other exception concerned decisions about large purchases above 5,000 Tshs, as 42.8 percent of participants believed this power should lie solely with the male. While these two questions suggest a long-established distinction in the sexual division of labor, they also suggest that women have recognized decision-making powers in some circumstances.

Question 5.4 states that, 'It is acceptable for a man to beat his wife when she refuses to have sex or perform a sexual act.' Marital rape occurs frequently in Kilimanjaro and women have neither legal protection nor the voice to condemn such behavior. Here, 9.8 percent of females strongly agree with this statement in comparison to 4.8 percent of men. On the other end of the spectrum, 28.0 percent of females strongly disagreed with this statement compared to 12.0 percent of males. Thus, the data highlight the complexity of the prevailing attitudes towards GBV and emphasize the need for further research, interventions, and education.

Interestingly, women had mixed and sometimes negative thoughts towards the questions which attest to their legal equality. For example, question 5.7 states that "Women should be able to get divorced whenever they want to." While this is a right guaranteed by the constitution of the Republic of Tanzania, 33.2\% of women who experienced GBV in the last 12 months strongly disagreed with this statement. Among men and women who have never experienced GBV, 83.3\% of women strongly agree with the statement, while only 37.8 percent of women strongly agree. This information is hugely significant as it suggests that substantial degrees of social acceptability for statutory laws that violate female equality are upheld by women. This poses several implications for prevention and intervention strategies.

The percentages of men and women who believe that women should hold equal decision-making power within the household also sheds important light regarding attitudes towards GBV.32.6 percent of men either strongly disagreed or disagreed with this idea, while only 10.3 percent of women either strongly disagreed or disagreed with the statement. Furthermore, 80.1 percent of women either agreed or strongly agreed with this statement, perhaps suggesting that women are dissatisfied with their relative lack of decision-making privileges. Concomitantly, 74.5 percent of men either strongly agree or agree with this statement. Here, both men and women suggest they ascribe to 
the belief that women should be able to make decisions, although the data suggest that women feel slightly stronger about this belief than their male counterparts.

\section{Limitations}

While a sample size of 384 is considered representative for the given population with a five percent margin of error, a larger sample would yield more accurate data. Additionally, while a survey was considered to be the most effective means through which participants could honestly convey information and opinions of a sensitive nature, qualitative interviews and focus group discussions would have provided greater insight into the complexity of attitudes towards GBV in the Kilimanjaro region, perhaps in areas where data was inconclusive. Four of the five wards surveyed are classified as rural, while Tarakea Motamburu is considered a mixed ward. Both districts are overwhelmingly rural, as is the Kilimanjaro region. However, it is important to note that this study did not include the Moshi Urban region and, thus, cannot identify relationships between socio-demographic variables and GBV in an urban setting.

A third limitation is the likelihood of under-reporting, which might be attributed to any number of reasons. While the surveys were administered by trusted and respected local government authorities, this did not necessarily imply that participants felt comfortable in revealing the complete truth. Because silence is a common problem among both perpetrators and victims of GBV, there was undoubtedly some degree of under-reporting. Additionally, because participants were attending workshops to educate and promote human rights and because the surveys were linked to an NGO that promotes female equality, it is likely that participants were aware of the assumed principles of the investigator and her research team. It is plausible that those who interacted with the research team perhaps felt pressured, even unconsciously, to report answers congruent with those of the investigator and KWIECO.

\section{Implications for further research}

Attitudes towards GBV did not vary significantly according to age, thus challenging the common assumption that elder members of the community are less progressive. Accordingly, it is critical to continue community outreach to all sectors of the population. Interventions should also continue to target youth who will eventually become the adults who either maintain the status quo or abandon old cultural beliefs in favor of more egalitarian customs and practices. What is lacking, perhaps, is interventions among victims of GBV as results indicated that this sector of the population are among the most tolerant of GBV.

Data confirmed the link between violence and alcoholism. In Kilimanjaro, few services 
are available to individuals who suffer from alcoholism and a fundamental understanding of addiction is scarce. In targeting the root causes of GBV, it will be essential to target the problem alcoholism. This will not be easy. In Mrao Keryo, there are with twenty-eight different types of local brew. Interventions that focus on women's rights would perhaps be more effective in combating GBV if facilitators included a dialogue regarding the deleterious effects of alcohol on the preservation of an individual's human rights.

Additionally, data indicated that women who generate an income are far less likely to experience GBV. As previously stated, the vast majority of participants surveyed were agricultural laborers who were well below the poverty line for the developing world. Not only does a woman's income lessen the financial burden of the household and reduce stress among its members, it enhances a woman's social mobility, potentially allowing her to leave abusive relationships. Data also indicated a strong correlation between violence against females and the number of deceased children per household. Issues such as infant mortality, malaria related deaths, and access to services highlight an ongoing need to improve the standard of living as a family of healthier children may lead to a decrease in gender-based violence.

\section{Conclusion}

While defining the correlates of GBV is a fairly simple endeavor, understanding individual beliefs and attitudes within the larger community is a more arduous task. Nevertheless, there are some large-scale implications to consider. GBV exists in virtually every society. It is both engrained in and a creator of culture. Yet combating gender-based violence is remarkably more challenging in a nation in which women already face discrimination and cultural subjugation. Legal equality not diluted by ambiguous diction or diminished by dominant religious and ethnic beliefs, is the way forward in creating a society in which gender equality is a cultural value. This is especially difficult in communities in which the status quo is upheld by wide ranging segments of the population. Many attitudes and beliefs regarding legal inequality were supported by women. This poses a host of complications and suggests that interventions should be targeted towards men and women, in perhaps gender-specific interventions which can more effectively target the root of the problem.

It is indisputable that poverty facilitates a host of other harms. However, the problem of poverty in Tanzania is only compounded by a culture that only invests in fifty percent of its population. What many fail to recognize is that investing in the well-being and livelihood of women is synonymous with investing in Tanzania as a whole. All segments of the population, whether male or female, need interventions to promote this notion. A society that values women and utilizes their capabilities in all sectors of the nation - from government to medicine to land ownership and beyond - will surely rise in economic prosperity which will, in turn, ameliorate many of problems tangential to GBV. 


\section{Acknowledgements}

I am foremost grateful to the staff at KWIECO for the opportunity to conduct this study. Specifically, I would like to thank Martin Kilasara for his helpful editing and comments, Hilary Tesha and Anna Gabriel for their hospitality and support in the field, and Mama Aginatha Rutazaa - my mentor and director - for her endless advisement and her commitment to my experience conducting this research. I acknowledge Mama Alice Kangwa, my Kiswahili teacher and confidant, who assisted in translating the survey. Data collection in Rombo would not have been possible without the help of the Ward Executive Officers, Epimack Mrina, Clementina, and Kimario. For their assistance in Uru Shimbwe, I would like to thank Mitra Lebastchi and Romana Olomi of Minjeni Women's Group and Susanna Temba and Bernardi Mlay for their dedication in administering surveys. And in Mabogini, I am indebted to Amanda Filipuzuk-Baker and Rahabu James of Tusaidiane for inviting me to administer surveys at their women's group. Lastly, I am grateful to the men and women in Kilimanjaro who participated in the surveys and gracefully welcomed me into their communities.

\section{References}

Bastien, S., 2005, 'The Construction of Gender in Times of Change: A Case Study of School-Based HIV/AIDS Education in Kilimanjaro', Master's dissertation, Institute for Educational Research, University of Oslo.

Gonzalez-Brenes, M., 2004, 'Domestic Violence and Household Decision-making: Evidence from East Africa', Ph.D. Dissertation, Department of Economics, University of California Berkeley.

Heise, L., Ellsberg M., and Gottemoeller, M., 1998, 'Violence Against Women: an Integrated, Ecological Framework', Violence Against Women, Vol. 4, pp. 262 290.

Heise, L., 2002, 'A Global Overview of Gender-based Violence', International Journal of Gynecology and Obstetrics, Vol. 78, Supplement 1, pp. S5-S14.

Hinden, M., 2003, 'Understanding Women's Attitudes Wife Beating in Zimbabwe', Bulletin of the World Health Organization, Vol. 81, pp. 501-508.

Kijo-Bisimba, H., N.d., 'Major Laws Relating to Women's Lives', Legal and Human Rights Center, http://tanzania.fes-international.de/doc/wr-major-laws.pdf.

Kimuna, S.R., and Djamba, Y.K., 2008, 'Gender-Based Violence: Correlates of Physical and Sexual Wife Abuse in Kenya', Journal of Family Violence, Vol. 23, No. 1, pp. 333-342.

McCloskley, L., Williams, C., and Larsen, U., N.d., 'Relationship Characteristics Associated with Intimate Partner Violence in Moshi, Tanzania', Department 
of Society, Human Development, and Health, Harvard School of Public Health.

Ministry of Planning, Economy, and Empowerment, 2006, 'Status Report: National Strategy for Growth and Reduction of Poverty', United Republic of Tanzania. Mzinga,J., 2002, 'Changing Gender Roles in Tanzania', Sexual Health Exchange, Vol. 4. National Bureau of Statistics, 2002, Kilimanjaro Region Socio-Economic Profile $\left(2^{\text {nd }}\right.$ Ed.), Kilimanjaro Regional Commissioner's Office.

Parliament of the United Republic of Tanzania, 1 July 2008, Sexual Offences Special Provisions Act, No. 4.

Population and Housing Census, 2002, 'Population by Village, 5 Year Age Group and Sex', United Republic of Tanzania.

Rutazaa, A., 2005, 'Tanzanian Women and Access to Law: The Case of Kilimanjaro', Durham, North Carolina, Terry Sanford Institute of Public Policy, Duke University.

Uthman, O., Lawoko, S., and Moradi, T., 2009, 'Factors Associated with Attitudes Towards Intimate Partner Violence Against Women: A Comparative Analysis of 17 sub-Saharan Countries', Social Science and Medicine, Vol. 68, No. 10, pp. 1801-1809 